\title{
Chronic Hyperglycemia Reduces Surface Active Material Flux in Tracheal Fluid of Fetal Lambs
}

\author{
David Warburton, Neonatal-Respiratory Disease Division, Department of \\ Pediatrics, University of Southern California School of Medicine, Children's \\ Hospital of Los Angeles, Los Angeles, California 90027
}

A B S T R A C T I tested the hypothesis that chronic hyperglycemia alters fetal lung maturation by continuous infusion of glucose $(14 \pm 2 \mathrm{mg} / \mathrm{kg}$ per min, mean $\pm \mathrm{SE})$ from 112 up to $145 \mathrm{~d}$ gestation into six chronically catheterized fetal lambs from which tracheal fluid could be collected. Serum glucose levels $(32 \pm 2 \mathrm{mg} / \mathrm{dl})$ and serum insulin levels $(38 \pm 4 \mu \mathrm{U} / \mathrm{ml})$ in these glucose-treated fetuses were significantly higher than serum glucose levels $(18 \pm 2 \mathrm{mg} / \mathrm{dl}, P<0.001)$ and serum insulin levels $(12 \pm 3 \mu \mathrm{U} / \mathrm{ml}, P<0.001)$ in six chronically catheterized control fetuses of the same gestational ages. Glucose infusion to the fetuses did not alter maternal serum glucose $(60 \pm 3 \mathrm{mg} / \mathrm{dl})$ or serum insulin levels $(35 \pm 5 \mu \mathrm{U} / \mathrm{ml})$. Arterial blood gases $(\mathrm{pH}$ 7.34 $\pm 0.01, \mathrm{PO}_{2} 24.3 \pm 0.5 \mathrm{mmHg}, \mathrm{PCO}_{2} 41.5 \pm 0.9$ $\mathrm{mmHg})$, oxygen saturation $(73 \pm 2 \%)$, hematocrit $(31 \pm 1 \%)$, and tracheal fluid flow $(2.4 \pm 0.1 \mathrm{ml} / \mathrm{g}$ per $\mathrm{h})$ in the glucose-treated fetuses were not significantly different from controls. Among the control fetuses, surface active material (SAM) began to appear in tracheal fluid at $123 \mathrm{~d}$ gestation and was present in all six fetuses by $129 \mathrm{~d}$ gestation, whereas SAM did not appear at all in tracheal fluid of four of the glucosetreated fetuses, and appeared in two at low levels after $142 \mathrm{~d}$ gestation. SAM flux in the glucose-treated fetuses $(<1 \mu \mathrm{g} / \mathrm{g}$ per $\mathrm{h}$ ) was statistically lower than SAM flux in the control fetuses $(60 \pm 9 \mu \mathrm{g} / \mathrm{kg}$ per $\mathrm{h}, P<0.001)$. Between 130 and 140 d gestation, tracheal fluid phospholipid content rose fourfold, mixed lecithin content rose ninefold, disaturated phosphatidylcholine content rose fourfold in the control fetuses, whereas little or no increase in these measurements occurred in the glucose-treated fetuses (all differences significant). I conclude that chronic hyperglycemia with secondary hyperinsulinemia reduces SAM flux in tracheal fluid

This work was presented in part before the Society for Pediatric Research, May 1982, Washington, DC.

Received for publication 27 May 1982 and in revised form 18 November 1982. of fetal lambs. The reduction in SAM flux is attributed to low surface active phospholipid content of the SAM. A similar mechanism may operate in utero to cause respiratory distress in infants of diabetic mothers whose maternal glucose homeostasis is poorly controlled.

\section{INTRODUCTION}

The incidence of respiratory distress syndrome (RDS) ${ }^{1}$ is reported by Robert et al. (1) to be increased almost sixfold in infants of diabetic mothers (IDM), even when suitable corrections are made for gestational age. However, RDS may be less prevalent when maternal diabetes is mild and well controlled $(2,3)$. The IDM experiences hyperinsulinemia both in utero and in the postnatal period (4-7), particularly when glucose homeostasis is poor (8).

Stubbs and Stubbs (9) postulated that hyperinsulinemia may be the common link between maternal diabetes mellitus and RDS. Gross et al. (10) have reported that insulin delays the morphologic maturation of fetal rat lung in organ culture, causing a decrease in the number of lamellar bodies in alveolar type II cells. In addition, Smith et al. (11) have reported that insulin inhibits lecithin synthesis by cultured mixed fetal lung cells in the presence of glucocorticoids. However, Sosenko et al. (12) examined lungs obtained from fetuses of alloxan diabetic rabbit does and found surfactant to be functionally impaired in the presence of normal amounts of phosphatidylcholine. Also, Werthammer et al. (13) have suggested that cholesterol may be present in surfactant of IDM and may inhibit the surface active properties by altering the packing properties of the surface film. Disturbed structural maturation of the lung has also been described by Sosenko et al. (14) in fetuses of alloxan diabetic rabbits.

\footnotetext{
${ }^{1}$ Abbreviations used in this paper: IDM, infants of diabetic mothers; RDS, respiratory distress syndrome; SAM, surface active material.
} 
In contrast, Epstein et al. (15) found increased rates of incorporation of choline into phosphatidylcholine in lung slices obtained from premature fetuses of glucose-intolerant rhesus monkeys.

Warburton et al. (16) recently reported that primary hyperinsulinemia reduces surface active material flux in tracheal fluid of fetal lambs. However, the insulintreated lambs in this study became hypoglycemic relative to controls. Hence, the reduction in surface active material flux could not be attributed solely to hyperinsulinemia. Moreover, in the human IDM, hyperglycemia rather than hypoglycemia occurs in utero in response to poor maternal glucose homeostasis, although hypoglycemia commonly occurs postnatally.

Because the role of hyperglycemia in the etiology of RDS among IDM is not fully understood, I sought to test the hypothesis that chronic hyperglycemia reduces the flux of surface active materials into tracheal fluid by infusing glucose into chronically catheterized fetal lambs from which tracheal fluid could be collected.

\section{METHODS}

Gestational age of fetal lambs was determined from the time of mating (Nebeker Farms, Santa Monica, CA). In addition, fetal age was estimated from ossification centers in utero, and by extrapolation of fetal weight and crown-rump measurements at delivery; dating by these methods agreed within $3 \mathrm{~d}$.

Between 108 and $110 \mathrm{~d}$ of pregnancy, ewes were operated upon under $0.5 \%$ xylocaine epidural anesthesia, as described by Platzker et al. (17). Polyvinyl chloride catheters were placed in a fetal carotid artery and jugular vein. A stiff polyethylene catheter was inserted into the fetal trachea. This catheter led to a $600-\mathrm{ml}$ latex bag that was left in the amniotic sac. A separate catheter leading from the latex bag, together with the fetal artery and vein catheters, was brought out through the ewe's flank. This arrangement allowed for the removal of accumulated tracheal fluid without applying negative pressure to the lungs, to obtain intermittent arterial blood gas samples from the fetus, and to give intravenous infusions to the fetus. A polyvinyl chloride catheter was also placed in a maternal vein. After the operation, the ewes received 1.2 million units procaine penicillin and $1 \mathrm{~g}$ kanamycin (Bristol Laboratories, Syracuse, NY) intramuscularly for $5 \mathrm{~d}$. The animals were allowed to recover for up to $3 \mathrm{~d}$ after the operation. The fetuses received 200,000 units penicillin $\mathrm{G}$ and $10 \mathrm{mg}$ kanamycin intravenously every day.

Hyperglycemia was induced by continuous intravenous infusion of $20 \%$ dextrose in water (American Hospital Supply Corp., Irvine, CA) using a constant infusion pump (IVAC Corporation, San Diego, CA). Glucose infusions were given to three singletons and to one twin fetus from each of three twin pregnancies. Three additional singletons and the three untreated twins served as controls.

Arterial blood samples $(3.5 \mathrm{ml} ; \sim 1 \%$ of fetal blood volume) were obtained every 48-72 h.

Tracheal fluid was collected daily and stored at $-40^{\circ} \mathrm{C}$ for subsequent analysis. The surface active material (SAM) in each tracheal fluid sample was measured on a surface balance (18). SAM flux, in micrograms per kilogram per hour, was calculated by multiplying the tracheal fluid SAM concentration in micrograms per milliliter by tracheal fluid flow in milligrams per kilogram per hour. Fetal weight was extrapolated from the fetal weight data of Barcroft, using the actual fetal weight measured at necropsy after fetal death (19)

Arterial blood gases were measured using a Corning 175 blood gas analyzer (Corning Medical, Medfield, MA). Arterial blood oxygen saturation was measured using a microoximeter (American Optical Co., Buffalo, NY). Serum samples were separated on these days and stored at $-40^{\circ} \mathrm{C}$ for subsequent analysis. Serum glucose concentration in milligrams per deciliter was measured by the glucose oxidase method using a YSI-23A glucose analyzer (Yellow Springs Instruments, Yellow Springs, $\mathrm{OH}$ ). Serum insulin concentration in microunits per milliliter was measured using a competitive binding radioimmunoassay (Beckton; Dickson Immunodiagnostics, Orangeburg, NY). Hematocrit of fetal blood was determined using a minicentrifuge (International Equipment Company, Needham Heights, MA).

Lipids were extracted from the tracheal fluid by the method of Bligh and Dyer (20). A 20,000-dpm aliquot of $\left.{ }^{14} \mathrm{C}\right]$-disaturated phosphatidylcholine $(50 \mu \mathrm{Ci} / \mu \mathrm{mol})$ (New England Nuclear, Boston, MA) was added during the lipid extraction step as a recovery standard. The extracted lipids were fractionated on thin-layer silica gel-G coated plates (Analtech, Inc., Newark, DE) activated for $2 \mathrm{~h}$ at $80^{\circ} \mathrm{C}$, using as a developing solvent a mixture of chloroform, methanol, and $7 \mathrm{~N}$ ammonium hydroxide (70:30:3.5) (Mallinckrodt, Inc., Paris, KY). Regions on the thin-layer plate corresponding to authentic samples of phosphatidylglycerol, phosphatidylinositol, phosphatidylethanolamine, phosphatidylserine, phosphatidylcholine, and sphingomyelin (Applied Sciences Laboratories, State College, PA) were visualized with iodine vapor and collected into scintillation vials. Disaturated phosphatidylcholine was isolated and its content measured from an aliquot of total phosphatidylcholine by the method of Mason et al. (21).

Radioactivity was measured using an aquasol (New England Nuclear)-based scintillation system in a Beckman LS 8100 liquid scintillation counter (Beckman Instruments, Inc., Palo Alto, CA). Counting efficiency was determined by the channels-ratio method. Phospholipid content was measured using the phosphorus assay method of Bartlett (22).

The serum insulin and serum glucose in the glucosetreated fetuses vs. the control fetuses were compared, respectively, using Student's $t$ test for unpaired data (23). Serum insulin and serum glucose levels in the mothers before and during glucose treatment of the fetuses were compared, respectively, using Student's $t$ test for paired data (23). SAM flux was compared using Wilcoxon's rank sum test for unpaired data (24). Phospholipid content of tracheal fluid was compared using Student's $t$ test for unpaired data (23).

\section{RESULTS}

Glucose infusions were given to three singleton and three twin fetuses at a rate of $14 \pm 2 \mathrm{mg} / \mathrm{kg}$ per min, mean $\pm S E$, from 112 through $130,135,139,140,143$, and $145 \mathrm{~d}$ gestation, respectively. Term in the sheep is $150 \mathrm{~d}$.

Serum glucose levels in the glucose-treated fetuses, $32 \pm 2 \mathrm{mg} / \mathrm{dl}$, were significantly elevated in comparison with serum glucose levels in the three singleton and three untreated twin control fetuses, $18 \pm 2 \mathrm{mg} / \mathrm{dl}, P$ 
$<0.001$. The serum glucose levels in the mothers were $60 \pm 3 \mathrm{mg} / \mathrm{dl}$ and did not change as a result of glucose infusion to the fetuses.

Serum insulin levels in the glucose-treated fetuses, $38 \pm 4 \mu \mathrm{U} / \mathrm{ml}$, were significantly elevated in comparison with serum insulin levels in the control fetuses, $12 \pm 3 \mu \mathrm{U} / \mathrm{ml}, P<0.001$. The maternal serum insulin levels of $35 \pm 5 \mu \mathrm{U} / \mathrm{ml}$ did not change as a result of glucose infusion to the fetuses.

Arterial blood gases in the glucose treated fetuses were $\mathrm{pH} 7.34 \pm 0.01, \mathrm{Po}_{2} 24.3 \pm 0.5 \mathrm{mmHg}, \mathrm{PCO}_{2}$ $41.5 \pm 0.9 \mathrm{mmHg}$. Oxygen saturation in the glucose treated fetuses were $73 \pm 2 \%$. Hematocrit in the glucose-treated fetuses was $31 \pm 1 \%$. Arterial blood gases, oxygen saturation, and hematocrit in the glucosetreated fetuses were not significantly different from the same values in the control fetuses. Hematocrit did not fall significantly during the experiment.

Serial data obtained from a pair of twin fetuses shown in Fig. 1 indicate that serum glucose and insulin levels became elevated following the start of the glucose infusion at $112 \mathrm{~d}$ gestation in the glucose-treated fetus. In addition, there were no significant differences in arterial blood $\mathrm{pH}, \mathrm{PCO}_{2}, \mathrm{Po}_{2}$, oxygen saturation and hematocrit between the glucose-treated and the control fetuses.

The rate of tracheal fluid production in the glucosetreated fetuses were $2.4 \pm 0.1 \mathrm{ml} / \mathrm{kg}$ per $\mathrm{h}$. The rate of tracheal fluid production in the controls was $2.8 \pm 0.1$ $\mathrm{ml} / \mathrm{kg}$ per $\mathrm{h}$ (not significantly different).

Fetal (intrauterine) death occurred in five of the six glucose-treated fetuses. Arterial blood gases were normal in each case $48 \mathrm{~h}$ or less prior to death. However, since arterial blood gases were not sampled more frequently than every 48 to $72 \mathrm{~h}$, data are not reported subsequent to the last known normal blood gas values. One pair of twins was delivered alive by cesarian section at 143-d gestation.

SAM flux into the tracheal fluid of the fetal lambs is shown in Fig. 2. SAM began to appear in the tracheal fluid of the control fetuses as $123 \mathrm{~d}$ gestation and was present in all six control fetuses by $132 \mathrm{~d}$ gestation. Thereafter, SAM flux rose rapidly to $75 \mu \mathrm{g} / \mathrm{kg}$ per h after the 140th $d$ of gestation in the control fetuses. In contrast, SAM did not appear at all in the tracheal fluid of four of the glucose-treated fetuses and only appeared at low levels after $142 \mathrm{~d}$ gestation in two of the glucose-treated fetuses. The reduction in SAM flux among the glucose-treated fetuses $(<1 \mu \mathrm{g} / \mathrm{kg}$ per h) was statistically significant in comparison with the control fetuses. $(60 \pm 9 \mu \mathrm{g} / \mathrm{kg}$ per $\mathrm{h}, P<0.001)$.

The phospholipids in the tracheal fluid were separated into four major fractions (Table I). The fraction represented as sphingomyelin is a mixture of sphingomyelin, phosphatidylserine, and phosphatidylinosi-

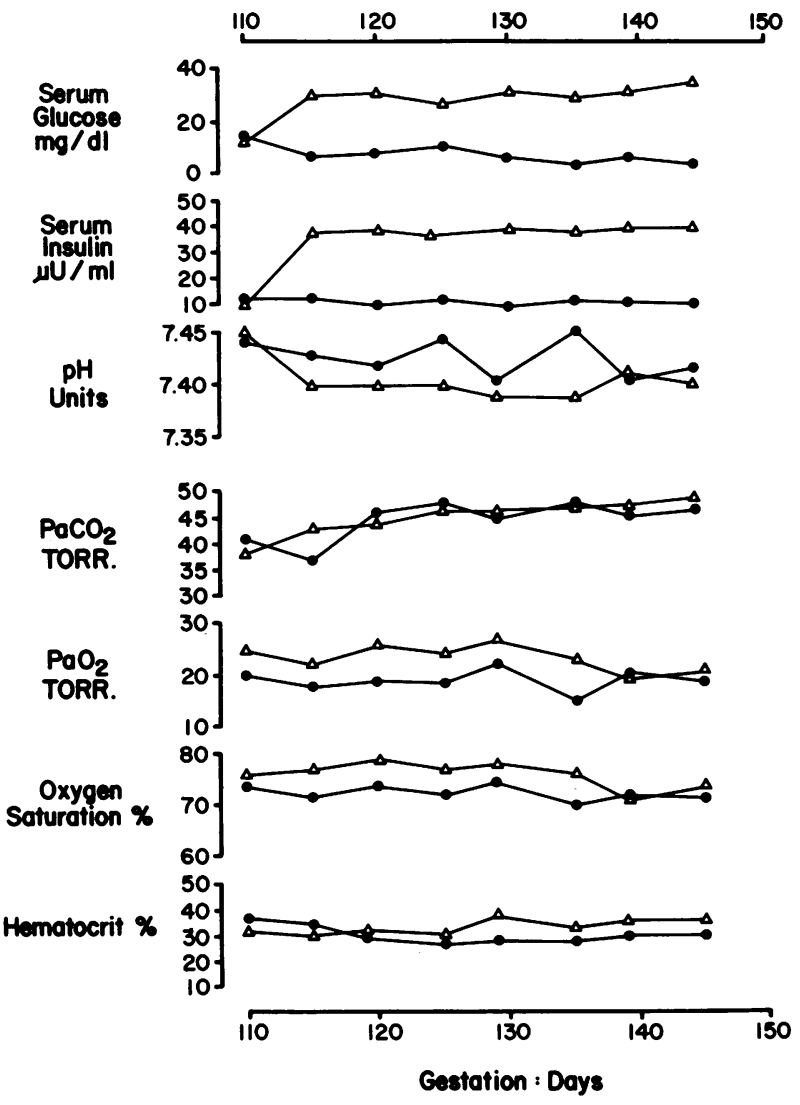

Figure 1 Serial serum glucose and insulin levels, arterial blood $\mathrm{pH}, \mathrm{PCO}_{2}, \mathrm{PO}_{2}$, oxygen saturation, and hematocrit in a pair of chronically catheterized twin lambs between 110 and $145 \mathrm{~d}$ gestation. Glucose was infused intravenously into one of the twins $(\Delta)$ from $112 \mathrm{~d}$ gestation onwards. The other twin (๑) served as a control.

tol, which were not completely separable by thin-layer chromatography.

Before $130 \mathrm{~d}$ gestation, the total phospholipid content of the tracheal fluid was similar in the control and glucose-treated fetuses. However, the mixed lecithin content of tracheal fluid from the glucose treated fetuses was only $34 \%$ of the content in control ( $P$ $<0.001$ ). Between $<130$ and $>140 \mathrm{~d}$ gestation, the mean tracheal fluid total phospholipid content rose fourfold, the mixed lecithin content rose ninefold, and the disaturated phosphatidylcholine content rose fourfold in the control fetuses, whereas little or no increase in these measurements occurred in the glucose-treated fetuses. During the same period of gestation, the phosphatidylglycerol content of tracheal fluid increased fourfold in the control fetuses, whereas phosphatidylglycerol was absent from the tracheal fluid of the glucose-treated fetuses. The tracheal fluid content of sphingomyelin and phosphatidylethanolamine in the 


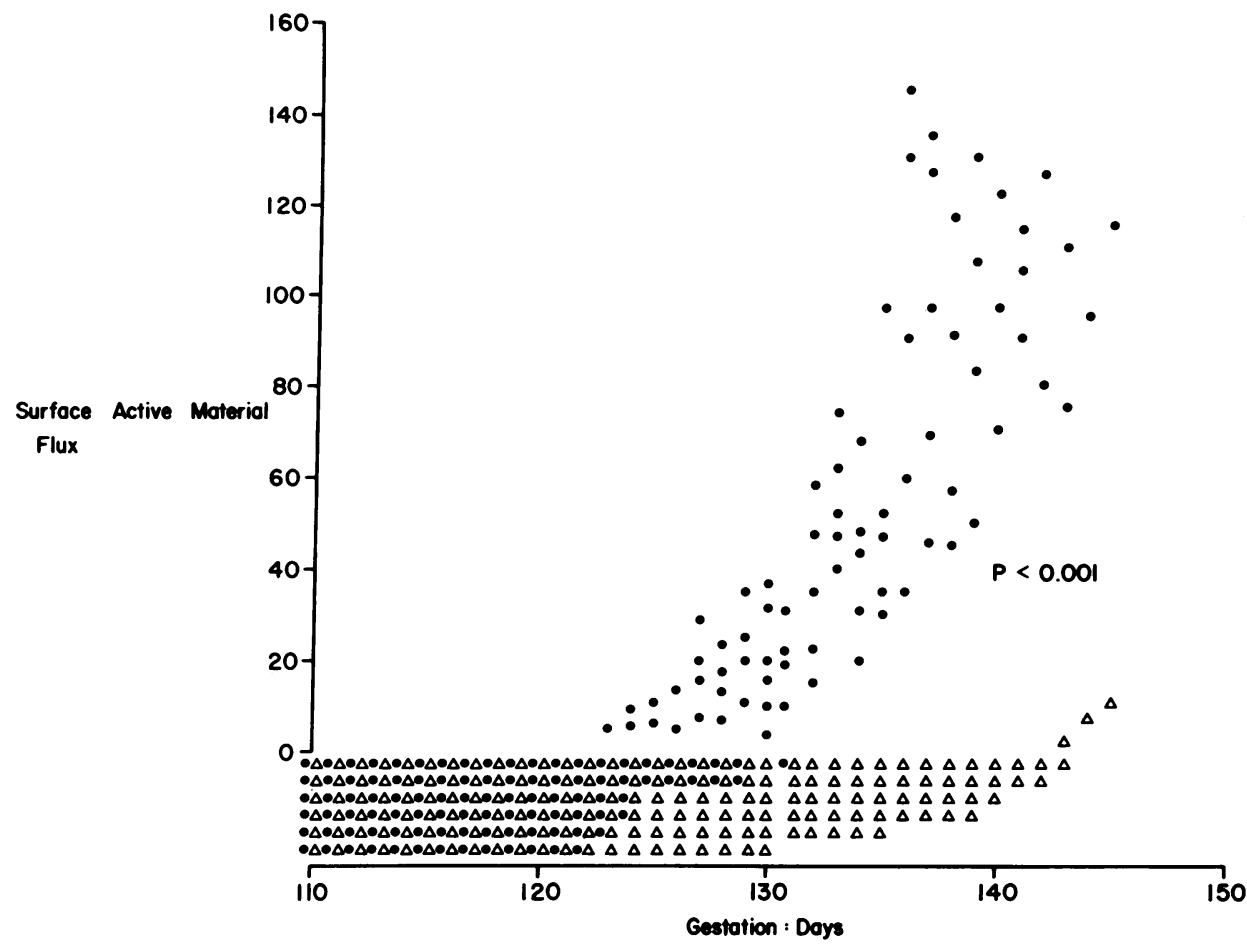

Figure 2 Surface active material flux (micrograms per kilogram per hour) into tracheal fluid of fetal lambs: comparison of glucose-treated $(\Delta)$ and control $(\bullet)$ fetuses between 110 and 145 d gestation. $P$ value refers to significant difference by Wilcoxon's rank sum test for unpaired data.

glucose-treated and control fetuses were not significantly different.

\section{DISCUSSION}

Continuous intravenous infusion of glucose produced significant elevation of serum glucose and insulin levels in six chronically catheterized fetal lambs. Philipps et al. (25) reported a fall in arterial oxygen content with chronic glucose infusion to fetal lambs. In the current study, arterial oxygen content was not measured. However, arterial blood gases, specifically $\mathrm{Po}_{2}$, arterial oxygen saturation, and hematocrit were not affected by

TABLE I

Phospholipid Content of Tracheal Fluid Surface Active Material, Collected Daily from Six Chronically Catheterized, Glucosetreated, and Six Control Fetal Lambs, Expressed as Micrograms of Phospholipid Phosphorus per Day (M $\pm S E)$

\begin{tabular}{|c|c|c|c|c|c|c|c|}
\hline Gestation & $\begin{array}{c}\text { Total } \\
\text { phospholipids }\end{array}$ & $\begin{array}{l}\text { Mixed } \\
\text { lecithin }\end{array}$ & $\begin{array}{c}\text { Disaturated } \\
\text { phosphatidyl- } \\
\text { choline }\end{array}$ & $\begin{array}{l}\text { Sphingo- } \\
\text { myelin }\end{array}$ & $\begin{array}{l}\text { Phosphatidyl- } \\
\text { glycerol }\end{array}$ & $\begin{array}{l}\text { Phosphatidyl } \\
\text { ethanol- } \\
\text { amine }\end{array}$ & \\
\hline \multicolumn{8}{|l|}{$d$} \\
\hline & $48.7 \pm 10.4$ & $13.1 \pm 1.3$ & $10.3 \pm 3.6$ & $3.8 \pm 0.7$ & $0.7 \pm 0.2$ & $1.9 \pm 0.4$ & Control fetuses \\
\hline \multirow[t]{3}{*}{$<130$} & \multicolumn{7}{|c|}{$P<0.001$} \\
\hline & $32.6 \pm 5.4$ & $4.5 \pm 0.2$ & $3.9 \pm 0.9$ & $2.0 \pm 0.4$ & $\mathbf{0}$ & $1.2 \pm 0.3$ & Glucose-treated fetuses \\
\hline & $66.7 \pm 9.6$ & $22.7 \pm 6.7$ & $26.2 \pm 7.0$ & $2.9 \pm 0.2$ & $1.5 \pm 0.2$ & $3.7 \pm 0.6$ & Control fetuses \\
\hline \multirow[t]{3}{*}{$130-140$} & \multicolumn{4}{|c|}{$P<0.001$} & & & \\
\hline & $30.1 \pm 2.5$ & $5.8 \pm 1.5$ & $3.8 \pm 1.3$ & $2.7 \pm 0.9$ & $\mathbf{0}$ & $1.6 \pm 0.3$ & Glucose-treated fetuses \\
\hline & $194.0 \pm 11.2$ & $112.2 \pm 8.3$ & $48.1 \pm 8.1$ & $1.9 \pm 0.3$ & $2.6 \pm 0.3$ & $2.3 \pm 0.2$ & Control fetuses \\
\hline \multirow[t]{2}{*}{$>140$} & \multicolumn{4}{|c|}{$P<0.001$} & & & \\
\hline & $31.7 \pm 8.8$ & $5.8 \pm 1.4$ & $3.0 \pm 0.9$ & $5.2 \pm 1.1$ & $\mathbf{0}$ & $3.9 \pm 0.3$ & Glucose-treated fetuses \\
\hline
\end{tabular}

$P$ values refer to statistically significant differences by Student's $t$ test for unpaired data. 
chronic glucose infusion. Metabolic acidosis has also been reported at high rates of glucose infusion in chronically catheterized fetal lambs (25). At the rates of glucose infusion reported here $(14 \pm 2 \mathrm{mg} / \mathrm{kg}$ per min) no acidosis was noted.

Chronic hyperglycemia with secondary hyperinsulinemia was associated with a significant reduction of SAM flux into tracheal fluid of fetal lambs without affecting the rate of tracheal fluid production. The lungs of the fetal lamb produce fluid that flows from the trachea as early as $94 \mathrm{~d}$ gestation (26). Lung fluid production continues until birth. Mean tracheal fluid production rates reported by other investigators have ranged from 2.2 to $4.5 \mathrm{ml} / \mathrm{kg}$ per $\mathrm{h}$. In the studies of Mescher et al. (26), SAM appeared in tracheal fluid between 124 and $133 \mathrm{~d}$ gestation, and its flux increased rapidly to $125 \mu \mathrm{g} / \mathrm{kg}$ per $\mathrm{h}$ at $148 \mathrm{~d}$ gestation. Platzker et al. (17) isolated small amounts of disaturated lecithin from lung homogenates of fetal lambs at $108 \mathrm{~d}$ gestation, although this method cannot specifically identify disaturated lecithin in SAM. Kikkawa et al. (27) reported that lamellar inclusion bodies are first visible on electron microscopy of alveolar type II cells in fetal lamb lungs at $113 \mathrm{~d}$ gestation. Lamellar inclusion bodies are the most probable storage form of pulmonary surfactant. Hence, in the current study, chronic hyperglycemia with secondary hyperinsulinemia was present from the probable time of inception of SAM synthesis and packaging for secretion.

Warburton et al. (16) have recently reported that primary hyperinsulinemia reduces surface active material flux in tracheal fluid of fetal lambs in the presence of intrauterine hypoglycemia. Taken together with the results of the current study, these data implicate hyperinsulinemia as an etiologic factor in the reduction of SAM flux.

However, the relationship between fetal hyperinsulinemia and inhibition of fetal lung maturation is complex. Neufeld et al. (28) found increased concentrations of insulin receptors as well as increased affinity of receptors for the hormone in circulating blood monocytes obtained from infants of gestational diabetic mothers. Neufeld et al. (29) have also demonstrated increased insulin binding in membranes obtained from lungs of fetuses from alloxan diabetic rabbit does. Stubbs and Stubbs (9) suggested a possible biochemical mechanism by which insulin might inhibit surfactant phospholipid synthesis. Activation of pyruvate dehydrogenase by insulin (30) would increase conversion of glucose to acetyl-coenzyme A, thereby decreasing production of intermediary metabolites such as glycerol-3-phosphate and dihydroxyacetone phosphate, which are necessary for the synthesis of complex lipids (31). The results of the current study indicate that decreased amounts of surface active phospholipids reach the tracheal fluid of fetal lambs subjected to chronic hyperglycemia with secondary hyperinsulinemia. Gross et al. (10) have suggested on the basis of biochemical studies on fetal rat lung organ cultures, that insulin stimulates the synthesis of cell membrane phospholipids while decreasing that of surfactant phospholipids, in particular disaturated phosphatidylcholine. However, the data from the current study will not differentiate between a disorder of SAM phospholipid synthesis, storage, or secretion.

I conclude that chronic hyperglycemia with secondary hyperinsulinemia reduces SAM flux in tracheal fluid of chronically catheterized fetal lambs. The reduction in SAM flux is attributed to reduced amounts of surface active phospholipids in the tracheal fluid. A similar mechanism may operate in utero to cause RDS in IDM whose maternal glucose homeostasis is poorly controlled.

\section{ACKNOWLEDGMENTS}

The author thanks Dr. Robert M. McAllister and Dr. Arnold C. G. Platzker for advice and encouragement, Elena $M$. Ganir and Teresita T. Saluna for technical assistance, and Helmi K. Haines for secretarial assistance.

This work was supported in part by Biomedical Research Support grant RR05469-18; by a grant-in-aid from the American Lung Association-American Thoracic Society and by a Special Emphasis Research Career Development Award in Obstetric, Perinatal, and Pediatric Aspects of Diabetes Mellitus, 1 KO1 AM 01130-01.

\section{REFERENCES}

1. Robert, M. F., R. K. Neff, J. P. Hubbell, H. W. Taeusch, and M. E. Avery. 1975. Association between maternal diabetes mellitus and the respiratory-distress syndrome in the newborn. N. Engl. J. Med. 294: 357-360.

2. Gabbe, S. G., J. H. Mestman, R. K. Freeman, R. K. Anderson, and R. I. Lowensohn. 1977. Management and outcome of pregnancy in class A diabetes mellitus. Am. J. Obstet. Gynecol. 127: 465-469.

3. Gabbe, S. G., J. H. Mestman, R. K. Freeman, V. T. Goebelsman, R. I. Lowensohn, D. Nochimson, C. Cetrulo, and E. F. Quilligan. 1977. Management and outcome of pregnancy in maternal diabetes mellitus class $B$ to $\mathbf{R}$. Am. J. Obstet. Gynecol. 129: 723-732.

4. Beard, R. W., R. C. Turner, and N. W. Oakley. 1971. Fetal response to glucose loading. Postgrad. Med. J. 47: 68-78.

5. Jorgensen, K. R., T. Deckert, L. Mølsted-Pederson, and J. Pederson. 1966. Insulin, insulin antibody, and glucose in plasma of newborn infants of diabetic women. Acta Endocrinol. 52: 154-167.

6. King, K. C., P. A. J. Adam, K. Yamaguchi, and R. Schwartz. 1974. Insulin response to arginine in normal newborn infants and infants of diabetic mothers. Diabetes. 23: 816-820.

7. Pederson, J., B. Bojsen-Møller, and H. Poulsen. 1954. Blood sugar in newborn infants of diabetic mothers. Acta Endocrinol. 15: 33-52.

8. Schwartz, R., and M. Cornblath. 1976. Disorders of Carbohydrate Metabolism in Infancy. W. B. Saunders Company, Philadelphia. 137-145. 
9. Stubbs, W. A., and S. M. Stubbs. 1978. Hyperinsulinemia, diabetes mellitus, and respiratory distress syndrome: a common link? Lancet. I: 308-309.

10. Gross, I., G. J. W. Smith, C. M. Wilson, W. M. Maniscalco, L. D. Ingleson, A. Brehier, and S. A. Rooney. 1980. The influence of hormones on the biochemical development of fetal rat lung organ culture II insulin. Pediatr. Res. 14: 834-838.

11. Smith, B. T., C. J. P. Giroud, and M. E. Avery. 1975. Insulin antagonism of cortisol action on lecithin synthesis by cultured fetal lung cells. J. Pediatr. 87: 953-955.

12. Sosenko, I. R., E. E. Lawson, V. Demotazz, and I. D. Frantz. 1980. Functional delay in lung maturation in fetuses of diabetic rabbits. J. Appl. Physiol. 48: 643-647.

13. Werthammer, J., I. R. S. Sosenko, M. D. Cunningham and I. D. Frantz. 1981. Surfactant cholesterol: a possible inhibitor of surface activity. Pediatr. Res. 15: 733. (Abstr.)

14. Sosenko, I. R. S., I. D. Frantz, R. J. Roberts, and B. Meyrick. 1980. Morphologic disturbance of lung maturation in fetuses of Alloxan diabetic rabbits. Am. Rev. Respir. Dis. 122: 687-696.

15. Epstein, M. F., P. M. Farrell, and R. A. Chez. 1976. Fetal lung lecithin metabolism in glucose-intolerant rhesus monkey pregnancy. Pediatr. 57: 722-728.

16. Warburton, D., C. D. Lew, and A. C. G. Platzker. 1981. Primary hyperinsulinemia reduces surface active material flux in tracheal fluid of fetal lambs. Pediatr. Res. 15: $1422-1424$.

17. Platzker, A. C. G., J. A. Kitterman, J. Mescher, J. A. Clements, and W. H. Tooley. 1975. Surfactant in the lung and tracheal fluid of the fetal lamb and acceleration of its appearance by dexamethosone. Pediatrics. 56: 554561 .

18. Clements, J. A., J. Nellenbogen, and H. J. Trahan. 1970. Pulmonary surfactant and evolution of the lungs. Science (Wash. DC). 169: 603-604.

19. Barcroft, J. 1947. Researchers on Pre-Natal Life. Charles C Thomas, Springfield, IL. I: 1, 20, 33.
20. Bligh, E. G., and W. J. Dyer. 1959. A rapid method of total lipid extraction and purification. Can. J. Biochem. Physiol. 37: 911-917.

21. Mason, R. J., J. Nellenbogen, and J. A. Clements. 1976. Isolation of disaturated phosphatidylcholine with osmium tetroxide. J. Lipid Res. 17: 281-284.

22. Bartlett, E. R. 1959. Phosphorus assay in column chromatography. J. Biol. Chem. 234: 466-468.

23. Student. 1908. Probable error of a mean. Biometrika. 6: $1-25$.

24. Wilcoxon, F. 1945. Individual comparisons by ranking methods. Biometrics Bull. 1: 80-91.

25. Philipps, A. F., J. W. Dubin, P. J. Matty, and J. R. Raye. 1981. Effects of chronic hyperglycemia in the fetal lamb. Pediatr. Res. 15: 638. (Abstract)

26. Mescher, E. J., A. C. G. Platzker, P. L. Ballard, J. A Kitterman, J. A. Clements, and W. H. Tooley. 1975 Ontogeny of tracheal fluid, pulmonary surfactant, and plasma corticoids in the fetal lamb. J. Appl. Physiol. 39: 1017-1021.

27. Kikkawa, Y., E. K. Motomoya, and C. D. Cook. 1965 The ultrastructure of the lungs of lambs. The relation of osmiophilic inclusions and alveolar lining layer to fetal maturation and experimentally produced respiratory distress. Am. J. Pathol. 47: 877-903.

28. Neufeld, N. D., S. A. Kaplan, B. M. Lippe, and M. Scott. 1978. Increased monocyte receptor binding of ${ }^{125}[\mathrm{I}]$ insulin in infants of gestational diabetic mothers. J. Clin. Endocrinol. Metab. 47: 590-595.

29. Neufeld, N. D., L. M. Corbo, and S. A. Kaplan. 1981. Plasma membrane insulin receptors in fetal rabbit lung. Pediatr. Res. 15: 1058-1062.

30. Randle, P. J., and R. H. Denton. 1973. Rate Control Processes of Biological Processes. D. D. Davies, editor. Symp. Soc. Exp. Biol. 27: 401-408.

31. Newsholme, E. A., and C. Start. 1973. Regulation in Metabolism. John Wiley and Sons, London. 210-214. 